\title{
CONSCIÊNCIA MORAL TRANSCENDENTE E EXPERIÊNCIA RELIGIOSA NA OBRA DE VIKTOR FRANKL
}

\author{
Transcendent moral conscience and \\ religious experience in the work of Viktor Frankl
}

Ivo Studart Pereira*

\section{RESUMO}

No presente trabalho, avaliamos como a tese de Viktor Emil Frankl sobre o caráter transcendente da consciência moral [Gewissen] constitui um argumentochave para elucidar sua visão de experiência religiosa. Trata-se de um debate que toca, de maneira singular, o pensamento teológico do filósofo e psiquiatra vienense, na medida em que, partindo de uma análise do fenômeno da responsabilidade humana, chega-se a uma peculiar noção de relacionamento entre homem e Deus. Nesse sentido, paralelamente, vislumbramos como o pensador em questão refuta as leituras psicológicas sobre a moralidade, ao mesmo tempo em que objeta contra teses centrais da psicanálise sobre o tema.

Palavras-chave: Viktor Frankl. Consciência moral. Transcendência. Experiência religiosa. Psicanálise.

\section{ABSTRACT}

The present article is an analysis of how Viktor Emil Frankl's thesis about the transcendent character of the moral conscience [Gewissen] constitutes a key argument to bring to light his visions on religious experience. It is a debate that encompasses, in a particular way, the theological thought of the Viennese philosopher and psychiatrist because it goes from an analysis of the human

* Psicólogo, Mestre em Filosofia pela Universidade Federal do Ceará. E-mail: <ivusp@ yahoo.com.br>.

\begin{tabular}{|l|l|l|l|l|l|}
\hline Teocomunicação & Porto Alegre & v. 44 & n. 3 & p. 418-432 & set.-dez. 2014 \\
\hline
\end{tabular}


responsibility phenomena to a peculiar notion of the relationship between men and God. In this sense, we can get a glimpse of how this thinker refutes the psychological readings on morality at the same time that he objects the central psychoanalytical thesis on this matter.

Keywords: Viktor Frankl. Moral Conscience. Transcendence. Religious Experience. Psychoanalysis.

A consciência como um fato psicológico imanente já nos remete, por si mesma, à transcendência; somente pode ser compreendida a partir da transcendência, somente como ela própria, de alguma forma, constituindo um fenômeno transcendente. ${ }^{1}$

O pensador austríaco Viktor Emil Frankl (1905-1997) foi o criador da chamada logoterapia, abordagem psicoterápica situada na tradição humanista e existencial e também conhecida como a terceira escola vienense de psicoterapia, precedida pela psicanálise freudiana e pela psicologia individual de Alfred Adler. Como psiquiatra e filósofo, Frankl foi autor de uma obra de vasto escopo, fonte de contribuições teóricas que tocam os domínios da psicologia, filosofia, educação e, também, da teologia, campo este de cujo confronto, segundo ele, ninguém que "leve a psicoterapia a sério" pode esquivar-se (FRANKL, 1992, p. 12). Nesse sentido, o presente trabalho tem o propósito de explicitar como Frankl, partindo de uma análise da consciência moral (Gewissen), interpreta o fenômeno da responsabilidade humana e chega à sua particular concepção de experiência religiosa.

Entendemos que o tema da consciência moral na obra de Frankl deve ser compreendido no contexto do arranjo sistemático de sua teoria, no interior da qual as categorias se organizam numa condição de dependência lógica entre si. Logo, devemos ter em mente algumas noções preliminares do quadro teórico da logoterapia, antes de abordamos mais diretamente o primeiro dos conceitos abordados neste artigo. Peter ${ }^{2}$ descreve em número de quatro as premissas fundamentais do sistema logoterápico: 1) O homem é ser espiritual-pessoal; 2) O homem é capaz de autodeterminar-se; 3) O homem, nessa autodeterminação, orienta-se,

1 FRANKL, V. E. A Presença Ignorada de Deus. Tradução de Walter Schlupp e Helga Reinhold. Petrópolis: Vozes, 1992.

2 PETER, Ricardo. Viktor Frankl: a antropologia como terapia. Tradução de Christina Stumer. São Paulo: Paulus, 1999.120p.(Coleção: Psicologia Prática) 
primariamente, para o sentido; e 4) A autotranscendência pertence de maneira essencial ao ser do homem. Isto é, o ser humano é livre, na acepção de que possui, por meio de sua dimensão espiritual, a capacidade de distanciar-se da pressão dos condicionantes biológicos, psicológicos e sociológicos e decidir-se sobre sua atitude pessoal a cada momento de sua vida. Vendo-se nesta condição de liberdade, o homem orienta-se para a realização do sentido, entendido enquanto conceito axiológico, tal como Frankl o concebeu. Em outras palavras, enquanto ser livre, vários possíveis se apresentam ao homem. Em cada situação concreta da vida humana, a série de possíveis se polariza, e o sentido sempre aparece como aquele "melhor possível". Trata-se, na nossa interpretação, da manifestação pontual e personalíssima (ad personam e ad situationem, como prefere o autor) do reino dos valores, na tensão entre os reinos do possível, do real e do dever-ser. ${ }^{3}$

Concluído este esclarecimento prévio, a fim de abordarmos o fenômeno da consciência moral, devemos, como ponto de partida, proceder ao questionamento a respeito do reconhecimento do sentido: afinal, como o homem pode compreender, valorativamente, que possibilidades têm ou não sentido diante de sua vontade livre? Trata-se, aqui, de uma indagação crucial, tendo em vista o fato de que o tema da compreensão e da interpretação do sentido - em outras palavras, o questionamento a respeito do "para-quê" da liberdade - terá implicações radicais no pensamento ético e ontológico de Frankl; implicações essas que se condensaram, essencialmente, em sua obra sobre psicologia e teologia, "A Presença Ignorada de Deus" (FRANKL, 1992), trabalho que, em 1948, lhe serviu como tese de doutoramento em filosofia. Frank1 sabe que boa parte das questões que afloram a partir dessa problemática ultrapassam o campo de uma fundamentação antropológica para a psicoterapia e se convertem em questões especificamente teológicas e filosóficas. Logo, reconhece que muitas dessas considerações não constituem, propriamente, o quadro teórico da logoterapia, a qual, por si, é e permanece como "um método e uma técnica de psicoterapia capaz de ser praticado mesmo por quem não subscreve" por completo suas teses metaclínicas. ${ }^{4}$

3 LUKAS, E. Prevenção Psicológica: a prevenção de crises e a proteção do mundo interior do ponto de vista da logoterapia. Tradução de Helga Hinkenickel Reinhold. Petrópolis: Vozes, 1989.

4 FRANKL, V. E. Fundamentos Antropológicos da Psicoterapia. Tradução de Renato Bittencourt. Rio de Janeiro: Zahar Editores, 1978. 
Numa linguagem marcada pelas influências da psicanálise, ao abordar o tema da consciência moral, Frankl procura, antes, "reabilitar" o conceito de inconsciente, reconhecendo que tal categoria, em Freud, permanecia restrita à descrição de um sofisticado funcionamento instintivo: na psicanálise, "o inconsciente era, primordialmente, um reservatório de instintividade reprimida". Nesse ponto, Frankl reafirma sua interpretação sobre a teoria freudiana, contemplando nesta um perigoso automatismo do aparelho psíquico, através de uma psicologia essencialmente atomística, energética e mecanicista. $\mathrm{O}$ inconsciente psicanalítico é sempre referido, na logoterapia, como o "inconsciente instintivo". A noção de "inconsciente", na logoterapia, pode, no entanto, ser mais bem compreendida através de um vocabulário fenomenológico, mais do que psicanalítico, já que se trata, para ele, de realidade "irrefletida", não reflexiva ou pré-reflexiva. Isto é, "por inconsciente não se deve entender nada mais do que não reflexivo. Apesar disso, pretendese dizer algo mais: pretende-se dizer também não reflexionável". 5 Ao inconsciente instintivo, Frankl contrapõe, sem o negar, o "inconsciente espiritual". Com "inconsciente espiritual", Frankl quer afirmar que a existência humana não se passa num plano preponderante de reflexão, de intelectualização, e que o "eu em si mesmo" é irreflexível e "assim, somente executável, 'existente' somente em suas execuções, como "realidade de execução",; isto é, que a "existência propriamente dita continua sendo um fenômeno primário [Urphänomen] não analisável e irredutível" (FRANKL, 1992, p. 23). A referência a "primário" diz respeito ao fato de que tal classe de fenômenos não pode ser esclarecida satisfatoriamente no plano ôntico, isto é, através de sua "redução no ôntico", mas apenas através, como veremos, da "transcendência para o ontológico" (idem). Isto é, o espiritual é inconsciente "na medida em que se 'absorve' na execução irrefletida dos atos espirituais" (FRANKL, 1978, p. 149), noção que pode ser ilustrada com a metáfora da visão e do ponto cego da retina:

Da mesma forma que, no local de origem da retina, ou seja, no ponto de entrada do nervo ótico, a retina tem seu 'ponto cego', assim também o espírito, precisamente na sua origem, é cego a toda auto-observação e auto reflexão; quando é totalmente primordial, completamente 'ele mesmo', é inconsciente de si mesmo. Ao

5 FRANKL, V. E. Logoterapia e Análise Existencial: textos de cinco décadas. Tradução de Jonas Pereira dos Santos. Campinas: Editorial Psy II, 1995. 
espírito, poderíamos aplicar o que se lê nos antigos vedas indianos: 'Aquilo que vê não pode ser visto; aquilo que ouve não pode ser escutado; e o que pensa não pode ser pensado' (FRANKL, 1992, p. 24).

Uma outra analogia utilizada por Frankl é: "Com a ajuda de um telescópio, podem-se observar todos os planetas do sol, com exceção de um: fica excluído o próprio planeta Terra" (idem). É sobre essa ideia de inconsciente espiritual que Frankl passa a conceber sua noção de consciência moral (Gewissen). Preferimos adicionar o termo "moral" no intuito de não haver confusão de conceitos com uma consciência cognitiva (Bewusstsein). De fato, a consciência moral é definida, na logoterapia, como o "órgão do sentido", a capacidade de intuir o melhor possível que uma pessoa singular, diante de uma situação concreta, poderá atualizar, sendo esse critério de "melhor" o critério de uma escolha de sentido que, como vimos, é único ad situationem e ad personam. Frankl defende que a consciência moral tem suas raízes no inconsciente espiritual, tendo em vista que as decisões humanas existencialmente autênticas não são produtos de interminável ocupação intelectual; são elas "irrefletidas" e "inconscientes" na acepção que acabamos de apresentar. A consciência é, nesse raciocínio, irracional, ou pré-lógica, e constitui, assim, uma "compreensão pré-moral dos valores, muito anterior a qualquer moral explícita" (idem, p. 26, grifos originais). Frankl chama a atenção para que todo "exame de consciência" só toma lugar a posteriori, sendo a deliberação da consciência, em última instância, inescrutável. Nesse diapasão, a consciência moral - ao contrário da consciência cognitiva (Bewusstsein), a qual tem acesso ao ser que é - vislumbra um ser que ainda não é (um possível), mas que é digno de vir a ser. Trata-se de um possível que merece ser realizado: um dever-ser. Nessa visada, nessa antecipação espiritual, a consciência moral é, funcionalmente, intuitiva. Referindo-se a um indivíduo singular sobre uma situação concreta, esse dever-ser não pode subsumir-se em nenhuma lei geral, formulada universalmente: "uma vida a partir da consciência é sempre uma vida absolutamente pessoal", dirigindo-se, sempre, a uma "situação absolutamente concreta, àquilo que possa importar em nossa existência única e individual: a consciência considera sempre o 'aqui' ('Da') concreto do meu 'ser' ('Sein') pessoal”' (idem, p. 28).

A tese central de Frankl, aqui, é a de que a consciência moral é transcendente, apresentando-se como fenômeno que não se esgota 
em sua realidade psicológica. A fim de evitar mal-entendidos sobre o que a logoterapia depreende da noção de transcendência da consciência - e antes de abordar esse tema mais diretamente -, devemos mostrar como Frankl fez questão de estabelecer as distinções fundamentais entre tal categoria e o superego freudiano, afastando tal instância psíquica das autênticas questões de consciência. $\mathrm{Na}$ logoterapia, o superego constitui uma identificação a uma lei que é da ordem da cultura, dos padrões de comportamento, da modulação introjetada de um agir socialmente aceitável (na forma da imago do pai). Do ponto de vista espiritual, contudo, o homem só pode ser considerado "ele próprio", quando deixa de ser impulsionado por tais formas de determinação, para, livre e autoconsciente diante delas, ser responsável. Para Frankl, a psicanálise, nesse sentido, ter-se-ia esforçado para "id-ficar" e "des-egoficar" o ser humano (idem, p. 19), isto é, reforçar os ditames pulsionais em detrimento da vontade livre do homem. A consciência, no entanto, é orientada para o sentido, e este não guarda relações de necessidade com os modelos estabelecidos de valores histórico-morais consolidados, podendo romper com o interdito da cultura ou com o modelo positivo de lei, se necessário: "consequentemente, se a consciência pode vir a ter a função de contradizer o superego, ela, certamente, não deverá ser confundida com ele". ${ }^{6}$ Isto é, como instância integrante de um aparelho psíquico que, para Frankl, não reconhece em seu quadro teórico as noções de liberdade, valor e sentido, o superego não poderia, em qualquer caso, estar orientado ao sentido, mas sim, a uma lei instituída psicologicamente.

No quadro teórico de uma interpretação psicodinâmica da consciência, o ser humano empenha-se na direção do comportamento moral somente no intuito de livrar-se do incômodo de uma consciência pesada ou, para nos atermos a uma terminologia psicodinâmica, o incômodo de um superego insatisfeito. Obviamente, uma tal visão do comportamento moral do homem desvia-se da questão central sobre a verdadeira moralidade, a qual se revela apenas quando o ser humano começa a agir em virtude de algo ou de alguém, e não por si mesmo, isto é, não para ter uma consciência tranquila ou fugir de uma consciência pesada (FRANKL, 1967, p. 42).

6 FRANKL, V. E. The Will to Meaning. Nova Iorque: Meridian Books. 1988 (Trechos neste trabalho traduzidos por Ivo Studart Pereira). 
A passagem acima quer resguardar o caráter de objetividade do sentido e afastar a interpretação de um funcionamento homeostático para as ações humanas. O primeiro diz respeito à tese de que o sentido não é inventado pelo homem, mas, sim, percebido por ele. A segunda se refere à refutação da ideia de que o ser humano é um sistema homeostático fechado, cujo único fim é o de recobrar o equilíbrio, livrando-se de tensões. Para Frankl, paz de espírito nunca poderia, então, ser um fim em si mesmo, sob pena de inautenticidade. O "funcionamento" de uma tal consciência não se identifica plenamente com quaisquer ideais humanos de autoconservação, nem de qualquer manutenção homeostática. A verdadeira moralidade, para Frankl, jamais poderá ser reduzida a leituras psicológicas, sejam elas de caráter psicanalítico ou comportamentalista. O comportamento ético autêntico não se deixa "explicar" pelos recortes particulares de uma ciência qualquer, no interior de cujo quadro teórico, tais fenômenos seriam sempre lidos como epifenômenos, de uma forma ou de outra, passíveis de uma "explicação" ou de um "esquematismo" causal: em qualquer desses casos, a decisão espiritual está sempre fora de questão. Não se trata, portanto, de um "instinto ético".

Os instintos vitais são sempre esquemáticos e têm um funcionamento voltado para o "geral". Isto é, o comportamento instintivo dos animais segue a "lei do maior número", só funciona para situações genéricas, em que o ambiente estimula um funcionamento esquemático que se repete, em maior ou menor grau, em todos os indivíduos da espécie; valendo lembrar que é exatamente para a sobrevivência dessa espécie que se dirigem os instintos: "o instinto vital coloca a individualidade em segundo plano" (FRANKL, 1992, p. 28). Ora, a consciência moral aponta para um alvo que nunca é geral, mas sempre individual e concreto, isto é, aponta para a situação única e personalíssima que desafia, com seu quadro de possíveis, um ser humano particular. A própria ideia de um "instinto ético" traduz uma contradição em termos, já que a noção de instinto vital se opõe, intrinsecamente, à ideia de liberdade. Nem diante do mundo objetivo do dever-ser, do qual se derivam as possibilidades de sentido, o homem se deixa determinar: no homem, a possibilidade de negação e de afirmação é válida tanto para o comportamento instintivo quanto para a ação moral: "Não existe um instinto moral no mesmo sentido da palavra de um instinto sexual; pois não sou impelido por uma consciência moral, mas tenho que me decidir diante dela" (FRANKL, 1995, p. 112). Os animais são idênticos a seus instintos (pois não têm liberdade de agir 
diferentemente do que estes comandam), enquanto que o ser humano "é" sua liberdade.

É desse ponto de vista que Frankl defende o caráter criativo da consciência em oposição ao caráter adaptativo do instinto. De modo reiterado, a consciência individual guia o indivíduo a fazer algo que contradiz os padrões estabelecidos de moralidade - os valores - de seu lugar histórico e social. Frankl vê aí - para além dos condicionantes histórico-sociais e a partir deles - que é a consciência humana a iniciadora de "revoluções", na medida em que constitui o ponto de partida para que sentidos únicos venham a tornar-se valores: "O sentido único de hoje é o valor universal de amanhã. É desse modo que as religiões são criadas e que os valores evoluem" (FRANKL, 1988, p. 63).

Reflitamos, agora, sobre o questionamento de Foulquié:

A laicização da moral tornou bastante difícil, senão impossível, o fundamento do dever. Mas, enquanto se admite, para o ser racional que somos, a faculdade de erguer-se à concepção de uma ordem ideal, permanece sempre a possibilidade de indicar às almas ávidas de perfeição o objetivo a atingir, de apresentá-lo aos outros como desejável. Rejeitando como vãs construções do espírito todo o mundo ideal, os existencialistas chegam a esta dolorosa contradição de precisarem escolher sem qualquer princípio de escolha, sem nenhum padrão que lhes permita julgar se escolheram bem ou mal. Eis o fundamento da angústia existencialista ${ }^{8}$ (FOULQUIÉ, 1961, p. 50, grifos nossos).

Estaria, realmente, o homem só diante da angústia da escolha? Por meio da tese da transcendência da consciência moral, o pai da logoterapia acredita que não. Ao entendermos a consciência moral como "geradora de responsabilidade", ${ }^{9}$ poderemos chegar à seguinte reflexão: que fundamento último pode vir a legitimar a consciência moral como guia, como critério de escolha, tendo em vista o caráter contingencial e de unicidade de cada situação sobre a qual ela agirá, indicando-nos o sentido a ser cumprido? Isto é, como a finitude de nossa condição humana pode chegar a essa "nãosolidão" em escolher?

7 FRANKL, V. E. Psicoterapia para Todos: uma psicoterapia coletiva para contrapor-se à neurose coletiva. Tradução de Antonio Allgayer. Petrópolis: Vozes, 1990.

8 FOULQUIÉ, P. O Existencialismo. São Paulo: Difusão Europeia do Livro, 1961.

9 FRANKL, V. E. Sede de Sentido. Tradução de Henrique Elfes. São Paulo: Quadrante, 2003b. 
Iniciando seu argumento a respeito da transcendência da consciência, o pai da logoterapia parte de uma citação da romancista austríaca Marie von Ebner-Eschenbach: "Sê senhor da tua vontade e servo da tua consciência!". A primeira parte desse imperativo reflete a condição originária de liberdade do homem: ser senhor da "própria vontade". Quanto à segunda parte do imperativo, surge a questão: que legitimidade normativa teria este fenômeno da consciência? Frankl defende que esse caráter imperativo da consciência - da qual devemos "ser servos" - só pode resultar do fato de que o homem, em sua autocompreensão, vem a experimentar tal fenômeno como algo que transcende a mera condição humana. Isto é, essa autocompreensão tenderia a interpretar a própria existência a partir da transcendência: apenas no reconhecimento de que a consciência constitui algo para além do eu, como "porta-voz de algo distinto de mim", é que seu caráter normativo se vê, para Frankl, legitimado.

Para Frankl, a consciência moral, em contraposição ao superego, não pode ser devidamente compreendida em sua facticidade psicológica. O homem "ouve" algo como a "voz da consciência", mas não é do próprio homem que "provém" a voz. Na verdade, não se trataria, propriamente, de uma "voz da consciência", já que "a consciência não poderia 'ter voz", pois "ela própria 'é' a voz, a voz da transcendência. Esta voz somente é ouvida pelo homem, ela não provém dele; ao contrário, somente o caráter transcendente da consciência faz com que possamos compreender o homem (...)" (FRANKL, 1992, p. 41). Logo, com essa "voz", não deveria haver algo como um monólogo. Essa experiência, pelo contrário, deve apontar ao homem algo distinto dele mesmo e, nesse movimento, é que o homem pode compreender a própria existência a partir da transcendência: "Sob este ângulo, o termo 'pessoa' adquiriria um novo significado, pois agora podemos dizer: através da consciência da pessoa humana per-sonat uma instância extra-humana" (idem). O latinismo intencional de Frankl deve ser compreendido na acepção de "soar através de", de "retumbar". Isto é, uma região extrahumana ressona através da consciência moral.

Assim como o umbigo humano, que, analisado em si, sem a referência a algo de anterior que transcenda aquela existência, pareceria algo sem sentido e despropositado, a explicação de uma gênese da consciência moral do homem num plano meramente psíquico falha. As "explicações" psicológicas para tal fenômeno permanecem, para Frankl, vãs, pois, para ele, a consciência só se mostra inteligível 
quando interpretada a partir de uma região para além do homem: para compreendermos a condição humana de liberdade, "é suficiente basearmo-nos na sua existencialidade, porém, para explicar a condição humana de ser responsável, precisamos recorrer à transcendentalidade de ter consciência". Nesse raciocínio, a consciência seria "o lado imanente de um todo transcendente" (idem, p. 42, grifos nossos). Questionando radicalmente o "perante quê" da responsabilidade do homem, Frank1 chega, primeiramente, à tese da irredutibilidade ôntica da consciência: "Para a problemática sobre a origem da consciência, não há nenhuma saída psicológica ou psicogenética, apenas uma resposta ontológica" (idem, p. 44). É aí que, para o pai da logoterapia, "o questionamento ético se transforma em religioso".

Para Frank1, o homem não religioso seria aquele que toma sua consciência na mera facticidade da dimensão psicológica, ignorando seu caráter essencialmente transcendente. Aceitando tal fenômeno na imanência, o homem irreligioso - que, obviamente, também experimenta a liberdade, a responsabilidade e o sentido - crê, contudo, que a consciência que lhe fala seja algo fundamentado em seu próprio ser. Ele não questiona além, não "pergunta pelo que é responsável, nem de onde provém sua consciência" (idem); não vai adiante, deixando de reconhecer que, para além do fato psicológico imanente, há a referência ao Absoluto, ao Todo transcendente, a que se nomeia Deus. Isto é, o homem irreligioso interpreta sua consciência como instância última, enquanto que o homem religioso a compreende como a penúltima, aquela que antecede esse "perante quê" da responsabilidade. A imagem que Frankl nos fornece para ilustrar essa ideia (idem, p. 43) é a de um montanhista - o homem em busca de sentido - que, em sua jornada, chega ao pico imediatamente inferior ao mais alto, lá parando. O cume mais alto se esconde na neblina, é invisível a ele, que para, exatamente, por não querer "perder o chão firme sob seus pés" (idem). Para Frankl, só a pessoa religiosa assume esse risco: a fé é um ato de decisão.

Retomando o questionamento já feito acima, sobre a finitude da condição humana e a não solidão diante da escolha, Frankl insiste em que o Eu jamais poderia funcionar como o próprio legislador ético: "Em última análise, não pode haver nenhum 'imperativo categórico' autônomo, pois todo imperativo categórico recebe sua legitimação exclusivamente da transcendência, e não da imanência" (idem, p. 44). Por trás de todo querer, existe um dever-ser ontologicamente anterior: nós não inventamos o dever-ser; somos, pelo contrário, interpelados pela 
sua pré-existência. Em outras palavras, para Frank1, não poderia haver o que chamamos de solipsismo axiológico:

Ser livre é pouco, ou nada, se não houver um 'para quê'. Porém, também ser responsável não é tudo, se não soubermos perante que somos responsáveis. Por conseguinte, da mesma forma que não podemos derivar dos impulsos (id) a vontade (eu), não podemos derivar do 'querer' [Wollen] o 'dever' (superego) 'já que', recordando as belas palavras de Goethe 'todo querer é apenas um querer, precisamente porque deveríamos fazê-lo', ou seja, todo ato da vontade pressupõe uma noção do que se deve fazer. Todo dever (Sollen), apesar de todo ato de querer (Wollen), de alguma forma, está sempre pressuposto. O dever precede ontologicamente o querer. Da mesma forma como só posso responder se me perguntarem, como toda resposta torna necessário um 'a quê', e este 'a quê' tem que ser anterior à resposta em si, o 'perante quê' de toda responsabilidade é anterior à própria responsabilidade (idem, p. 45, grifos nossos).

Isto é, a vontade livre do querer humano já é previamente inclinada para uma possibilidade de valor, para um dever-ser. Em outras palavras, só se pode querer o bem. Uma questão crucial aqui é a de que Frankl atribui à consciência moral, entendida sob o ponto de vista da transcendência, o papel de sintonizar o logos supratemporal - o universal do bem - com uma situação histórica concreta e única experimentada pelo indivíduo. $\mathrm{O}$ autor sustenta tal posição mesmo reconhecendo o caráter de finitude de nossa consciência: a falibilidade da consciência deve ser aceita. Contudo, se o homem pretende ser fiel à sua humanidade, não terá ele guia mais autêntico do que a própria consciência, a qual, para Frankl, é o verdadeiro intérprete da vida:

Esta [a consciência] deve 'adivinhar'; sua tarefa essencial é a sincronização da lei eterna universal com um caso singular que não se deixa subordinar a nenhuma regularidade. $\mathrm{O}$ saber, o intelecto não são capazes de executar tal tarefa, que compete à intuição, à divinação da consciência. De que serviriam leis e decretos? $\mathrm{Na}$ mesma proporção em que a consciência - o que existe de menos burocrático - se subtrai a tudo isso, sua exatidão e severidade se tornam mais fidedignas. Nenhum tribunal do mundo consegue inquirir tão minuciosamente e sentenciar tão duramente (FRANKL, 1978, p. 250). 
Frankl, nesse estado de coisas, "subverte" a teoria psicanalítica, ao afirmar que não há um eu ideal por detrás do superego: "Na realidade, Deus não é uma imago de pai, mas o pai é uma imago de Deus" (FRANKL, 1992, p. 46). O que há é o Tu de Deus (na acepção dialógica de Martin Buber, 1878-1965) por detrás da consciência moral. Deus se revela como o protótipo de toda paternidade; a relação pai-filho seria imagem da relação homem-Deus. Para Frankl, a psicanálise erra ao derivar a consciência da instintividade do id: "o ego puxa-se a si mesmo pelos cabelos do superego para sair do pântano do id" (idem, p. 45):

A responsabilidade faz parte dos fenômenos irredutíveis e indedutíveis do homem; a responsabilidade, assim como a espiritualidade e a liberdade, é um fenômeno originário e não um epifenômeno. Diante disso, a psicodinâmica tenta reduzir os fenômenos primários a instintos, enquanto a psicogenética procura deduzi-los de instintos, como não só se pudesse derivar o ego do id, mas também se pudesse reduzir o superego ao ego; desse modo, derivar-se-ia primeiro a vontade dos instintos, o querer da necessidade e depois o dever do querer, sem levar em conta que a consciência remete a algo que transcende o homem (FRANKL, 1995 , p. 110, grifos nossos).

É a partir daí que Frankl critica a noção de liberdade em JeanPaul Sartre (1905-1980), afirmando que, na visão do mencionado pensador, o homem projeta seu dever-ser no nada, numa tentativa de criar o homem a partir do homem, sem modelo pré-existente algum. Frankl frisa a semelhança de tal noção com um antigo truque indiano, em que um faquir faz crer que está subindo por uma corda que fora arremessada livremente no ar. Nesse raciocínio, fica clara a posição de Frankl em concluir que uma imagem adequada do homem jamais será satisfatoriamente concebida, se o ser humano for completamente compreendido na imanência: "A supressão de realidades metafísicas, tal como é praticada pela psicologia acadêmica, não permite uma caracterização adequada do 'objeto de pesquisa' homem", de modo que "justamente por isso, a logoterapia inclui elementos metafísicos na sua antropologia" - explica Lukas (2002, p. 18).

É, exatamente, na perspectiva da transcendência da consciência moral que Frankl compreende, "operacionalmente" o relacionamento humano com Deus, interpretando Este como "o interlocutor de nosso diálogo interior mais íntimo", em nossos momentos de "solidão última". 
A ideia de "diálogo", que Frankl diz usar nos termos da dialógica de Martin Buber, remete a um âmbito de envolvimento dessa ordem: a transcendência ressona, como vimos, e o homem também recorre, também se permite falar a essa transcendência, que, por meio da oração, se presentifica como o Tu divino (Frankl, 1995, p.112). Frankl, numa citação do Salmo 26, versículo 8, da Bíblia Vulgata, recorre à imagem do homem cujo coração fala a Deus:

Na prática, isto [o diálogo interior mais íntimo] quer dizer que quando alguém, na sua mais completa solidão e com o máximo de honestidade para consigo mesmo, pensa e fala no plano da interioridade, está-se dirigindo verdadeiramente a Deus (tibi cor meum loquitur). Pode ser crente ou ateu, pouco importa, porque 'operacionalmente', Deus se define, como aquele com quem, de uma maneira ou de outra, nós falamos. O crente se diferencia, portanto, do ateu apenas por não admitir a hipótese de que está falando consigo mesmo; acha, pelo contrário, que suas palavras alcançam alguém que não é idêntico a ele (FRANKL, 1978, p. 258).

Por fim, para Frankl, pode-se conceber tal atitude de três maneiras fundamentais. Nas situações (geralmente, as situações-limite; ou na própria vivência da oração) em que trava essa experiência, o homem pode achar que está, verdadeiramente, falando consigo mesmo, num inusitado solilóquio. Pode, aí, pensar, também, que tem o Absoluto, Deus, como seu interlocutor. Numa terceira interpretação, o homem acredita que fala sozinho diante do nada. A posição de Frankl, no entanto, vai no sentido de uma experiência pessoal de transcendência: "O homem precisa de solidão para perceber que não está sozinho, que nunca esteve sozinho; deve ter solidão para verificar que a sua fala consigo mesmo é e sempre foi um diálogo" (idem, p. 272). Retomando a filosofia dialógica de Buber, Frankl rememora que o Diálogo é que é fundante: profere-se a palavra-princípio Tu antes mesmo de ter-se reconhecida qualquer noção de Eu. E quando, aparentemente, não há mais alguém a quem recorrer ou com quem se falar, quando o homem parece pronunciar suas palavras de maior aflição diante do nada, é que fala ele com o Tu eterno. Essa é a "presença ignorada de Deus" no pensamento de Frankl: trata-se de um Tu eterno porque o homem, mesmo que de maneira inconsciente, sempre se dirigiu a esse Tu, e esse Tu sempre falou ao homem: "A primeira palavra que dizemos a esse Tu já é uma resposta" (idem). 
Cremos, por ora, ter demonstrado, minimamente, como a tese de Frankl sobre o caráter transcendente da consciência moral se revela enquanto um argumento-chave para elucidar sua visão de experiência religiosa. Trata-se de um debate que toca, de maneira singular, um aspecto crucial do pensamento teológico do filósofo e psiquiatra vienense, na medida em que, partindo de uma análise do fenômeno da responsabilidade humana, chega-se a uma noção particularmente compreensiva de relacionamento entre homem e Deus. Nesse sentido, na construção de seu argumento, vislumbramos como o pensador em questão refuta as leituras psicológicas sobre a moralidade, ao mesmo tempo em que objeta contra teses centrais da psicanálise sobre o tema, deixando claras as diferenças entre o superego freudiano e a consciência moral, bem como negando a "psicologização" de Deus, como protótipo imagético da autoridade e poder do pai na infância. Para Frankl, então, em seu caráter transcendente, a consciência moral "fala" ao homem a partir de uma região extra-humana, e o homem também "fala" a este Tu eterno, em um diálogo que se funda na vivência existencial concreta de cada vida humana.

\section{Referências}

FOULQUIÉ, P. O Existencialismo. São Paulo: Difusão Europeia do Livro, 1961.

FRANKL, V. E. . Psychotherapy and Existentialism. Nova Iorque: Washington Square Press, 1967 (Trechos neste trabalho traduzidos por Ivo Studart Pereira).

. Fundamentos Antropológicos da Psicoterapia. Tradução de Renato Bittencourt. Rio de Janeiro: Zahar Editores, 1978.

. Em Busca de Sentido. Tradução de Walter Schlupp e Carlos Aveline. Petrópolis: Vozes, 1985.

. The Will to Meaning. Nova Iorque: Meridian Books. 1988 (Trechos neste trabalho traduzidos por Ivo Studart Pereira).

. Psicoterapia para Todos: uma psicoterapia coletiva para contrapor-se à neuroe coletiva. Tradução de Antonio Allgayer. Petrópolis: Vozes, 1990.

. A Presença Ignorada de Deus. Tradução de Walter Schlupp e Helga Reinhold. Petrópolis: Vozes, 1992.

. Logoterapia e Análise Existencial: textos de cinco décadas. Tradução de Jonas Pereira dos Santos. Campinas: Editorial Psy II, 1995.

. Sede de Sentido. Tradução de Henrique Elfes. São Paulo: Quadrante, 2003b. 
LUKAS, E. Prevenção Psicológica: a prevenção de crises e a proteção do mundo interior do ponto de vista da logoterapia. Tradução de Helga Hinkenickel Reinhold. Petrópolis: Vozes, 1989b.

PETER, Ricardo. Viktor Frankl: a antropologia como terapia. Tradução de Christina Stumer. São Paulo: Paulus, 1999. 120p. (Coleção: Psicologia Prática).

Recebida: 02/06/2014

Avaliada: 05/08/2014 